\title{
Auto-adjusting Wing Mirrors Angles System Based on Fuzzy Logic Control
}

\author{
Faridoon Shabaninia \\ Electrical Engineering Department, Shiraz University \\ *Corresponding Auhtor:shabani@shirazu.ac.ir
}

Copyright (C) 2014 Horizon Research Publishing All rights reserved.

\begin{abstract}
Mirrors are smooth surfaced features of the car that provide additional visibility for the driver. In fact, an automobile cannot be easily guided without mirrors. There are two types of mirrors in cars, side-view mirrors and rear-view mirrors. Rear-view mirrors are installed to see rearward and side-view mirrors help drivers to see area behind and to the sides of vehicles. Although, these mirrors help for better vision, still there are regions called blind spots that a driver must be informed about them. Lots of accidents may happen as a result of no sight for these areas. A Common type of disruption in traffic, which leads sometimes to car crashing, is when the driver intends to leave the car park. As the car is being turned, the blind spot is growing larger and probability of accident is increasing. So, in this paper, we design a controller, based on fuzzy logic control (FLC), helps us to reduce the possibility of accident and traffic disruption. This system alters angels of side-view mirrors to compensate turning angle of the automobile, which results in changing blind spot into visible area.
\end{abstract}

Keywords Fuzzy Logic Control, Vehicle's Mirrors

\section{Introduction}

Mirrors are important parts of a car's guiding system. For the first time, a looking glass was used in a car as rear- view mirror by Marmon Motor Car Company's engineer ,Ray Harroun, in 1911[1]. He installed this mirror in order to see back. After that, from 1912 car manufacturers began to install this kind of mirror as a usual piece. Another type of mirror was used on the exterior part of motor vehicle to create better vision of behind and sides of the car. It was called side-view mirrors [2]. Although mirrors help drivers to have a better look at the areas behind them, there are still some areas away from sight that are called blind spots [3]. This area increases the probability of accident. As a result, there have been many efforts to change blind spot into visible area, such as using especial kinds of mirrors instead of the old one, and also using rear-view camera and sensors. For instance, "Fisheye mirrors", "Aspheric mirrors" and
"Panoramic rear-view mirrors"[4] are mirrors that can be replaced for regular mirrors to reduce size of blind spot. With all these utilities, we can reduce the possibility of car crashing.

Another way for eliminating blind region is mounting a system on side-view mirrors to make it auto-adjust. The performance of this system is shown in fig. 1. It is known that, in high speed situations, altering the angle of mirror is not good, but in low speed conditions, this alteration can provide good visibility for drivers. As an example of these conditions, consider the situation in which a car is parked between two other cars in the side of street, and the driver wants to leave this state. An angle is made between the car and direction of road as a result of turning the steer, and then it results in creating a blind spot that increase(s) disturbing in driving which it results in increasing possibility of accident. Via designing a system that can adjust the angle of side-view mirror, the blind region can be visible for driver.

Today, fuzzy control is one of the most common methods of control that is used in different cases. In fact, in many industrial problems due to their complexities, very huge mathematical equations and lack of detailed information of their models; modern control cannot be useful. Thus, fuzzy control's importance to handle such problems becomes evident. A huge variety of industrial manufacturers use this procedure in producing many of their products. For example, home appliances producers, air industries and car factories are some of these industries. For instance, many features of cars have been influenced by fuzzy logic control. Active and semi-active suspension systems [5], air conditioning for vehicle [6], design of smart car control systems [7] and auto braking mechanism are some examples of applications of fuzzy logic control in automobile industries. In this paper, fuzzy logic control method is applied for auto-adjustment system of wing mirror angle for a four-wheeled vehicle.

\section{Description of the System}

Concept of fuzzy sets was expressed by Zadeh [8]. Then this concept was entered into control science. Fuzzy control uses and manipulates non-accurate and linguistic 
information in many complex industrial procedures. There have been several examples of this method in engineering works, up to now [9]. As it is mentioned earlier, the aim of this paper is designing a system in which side mirrors adjust their angle to have better vision in leaving parking mode. Based on fuzzy control, it is essential to have some information about this problem. At first, performance of the system, linguistic information and membership functions are provided and then simulation of the system is expressed.

\section{Applying Fuzzy Logic Control to the System}

It should be mentioned that while the driver moves his/her car to leave side street parking, there are several characteristics that determine mode of leaving the park lot. These can be used as parameters in designing our system. Thus, we define our system based on these properties and experimental observations and then express membership functions for these parameters.

Consider the state that a car is parked between two other cars in the side of street. When the driver decides to leave the parking, he/she switches it on; now, the car is ready to move.

Our project consist of setting vehicle's side mirrors angles intelligently to rotate horizontally, based on the steering angle, speed, distance travelled by car, car gear status, turn signal lights so that ,the driver's visibility in the core area increases. In the following, we explain more about these features.

\subsection{Steering Angle}

In our system, measurement of this angle is performed by an instrument which is called gyroscope. When car is switched on, the system starts to work. At first, zero amount is set to $\theta$ and after that, changing in this angle is measured by gyroscope and added to $\theta$. From our observations the maximum amount of steering angle for leaving the side parking, as it can be seen in Fig. 2 is about $45^{\circ}$. Simultaneously with car tuning between $0^{\circ}$ and $45^{\circ}$, the angle of side mirror changes relatively from initial set angle to extremity value. If turning angle is maintained between $45^{\circ}$ and $90^{\circ}$, the mirror angle is still in maximum value. If $\theta$ exceeds $90^{\circ}$ the system is restarted and mirror angle gets back to its primary angle. In Fig. 3, membership function for steering angle is presented. We choose bell shape function which means we will consider small angles carefully.

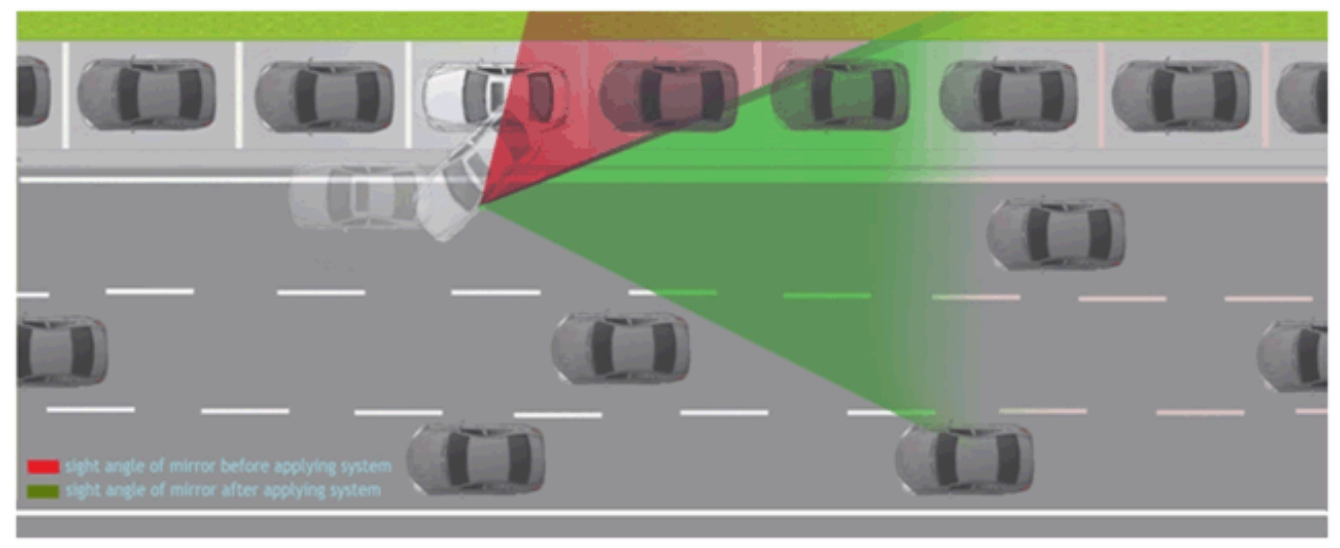

Figure 1. The schematic of visibility in side-view mirror before and after applying system.

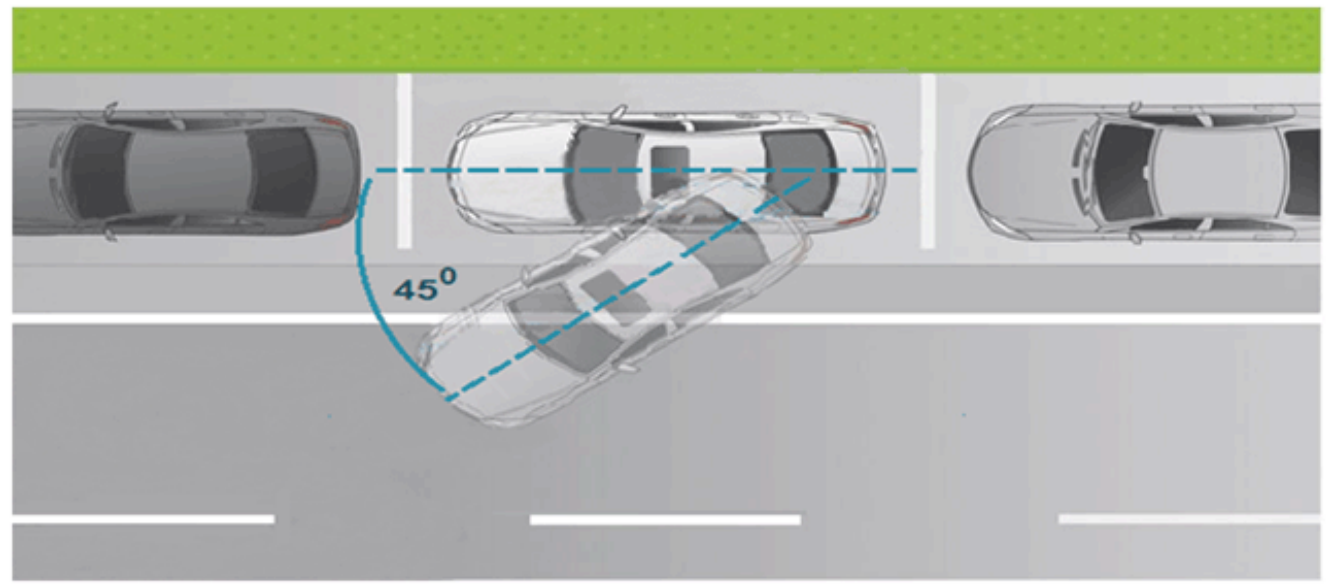

Figure 2. Maximum steering angle to leave Side Park. 


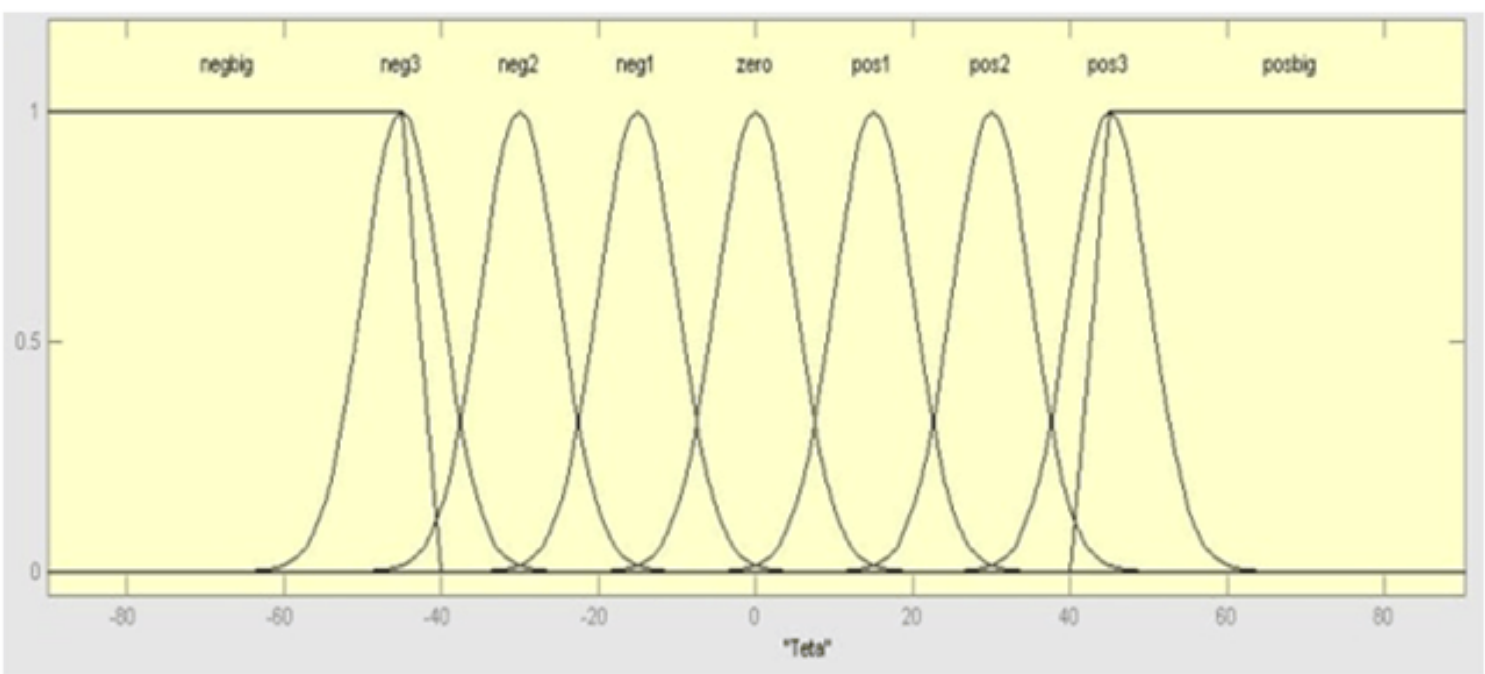

Figure 3. Membership function for steering angle $(\theta)$.

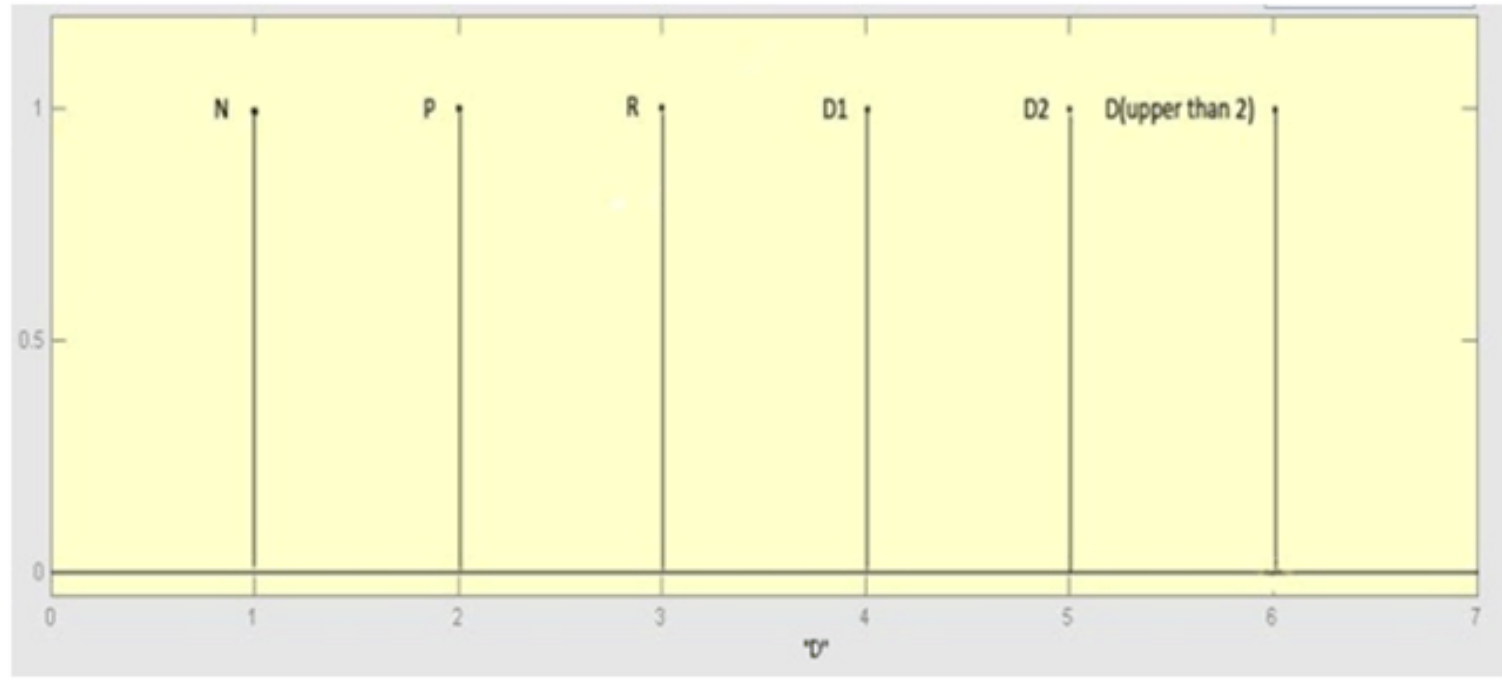

Figure 4. Membership function for car gear (singleton).

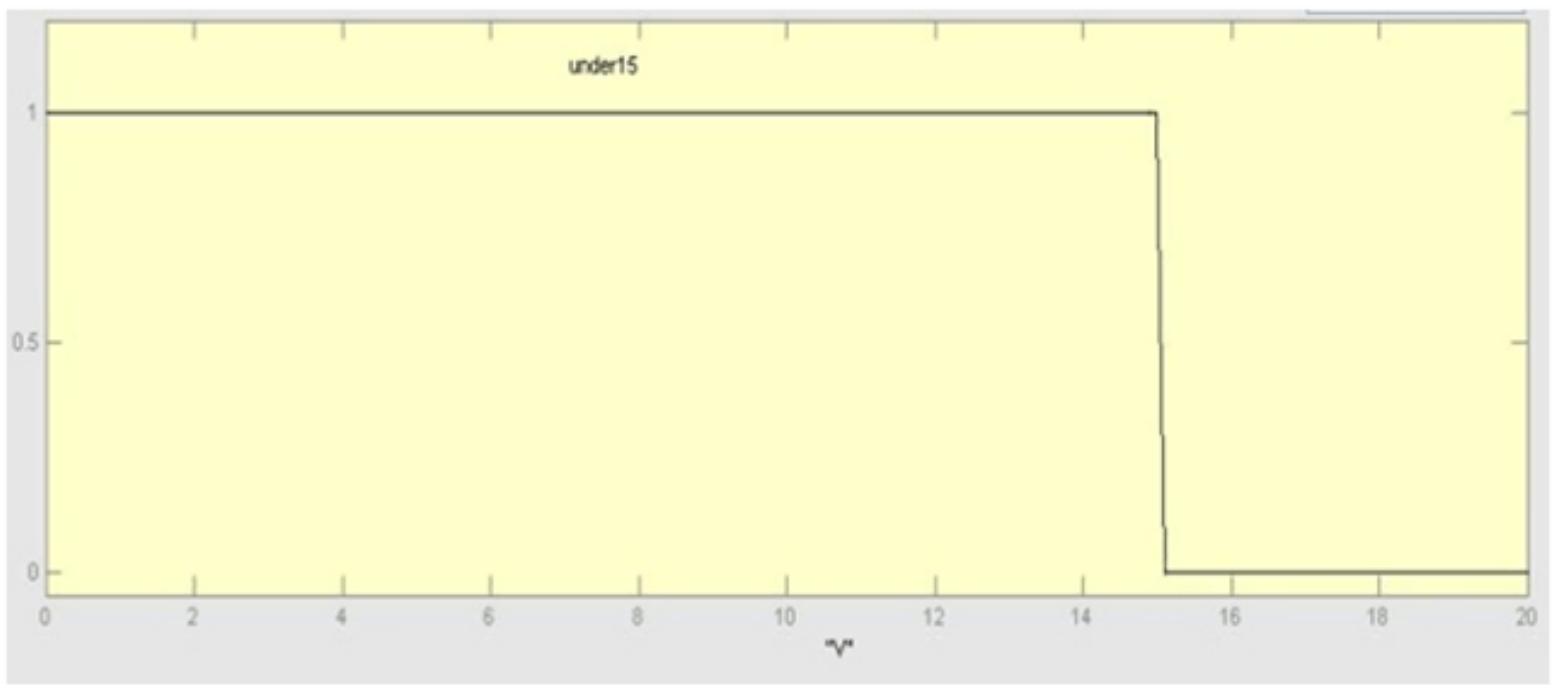

Figure 5. Membership function for car speed (v). 


\subsection{Car Gear}

It is known that car transmission system is divided in two categories, manual and automatic. To design auto-adjustment mirrors angles, both types of gears are considered. Car gear has four states, P (Park), and N (Neutral), R (Rear) and D (Drive) mode. The drive mode itself has five or six gears. While a car is stopped, the state of transmission is in park mode. After switching on a car to move, the driver must changes gear from neutral, park or rear mode to drive mode. At the moment of movement in automatic state first, forward gear is engaged and while the car is getting out of the side parking, still this gear is involved. In manual state, the driver may change the gear into second one. In this situation our system is still working. If the driver has to change car's gear to R mode while getting out of the parking, our system is stopped and other systems like turning downside mirrors angle for rear gear are activated, but when gear is changed to D mode, our system is operated and the mirror angle is adjusted based on steering angle. The membership function for car gear is showed in Fig.4. Type of this membership function is singleton.

\subsection{Car Speed}

In this article $\mathrm{V}$ is defined as speed of front wheel. This variable is a restricting parameter. From experiment, a maximum amount of $15 \mathrm{~km} / \mathrm{h}$ is considered for speed, such that the car cannot exceed this number during exiting side parking. The membership function of speed is shown in Fig. 5.

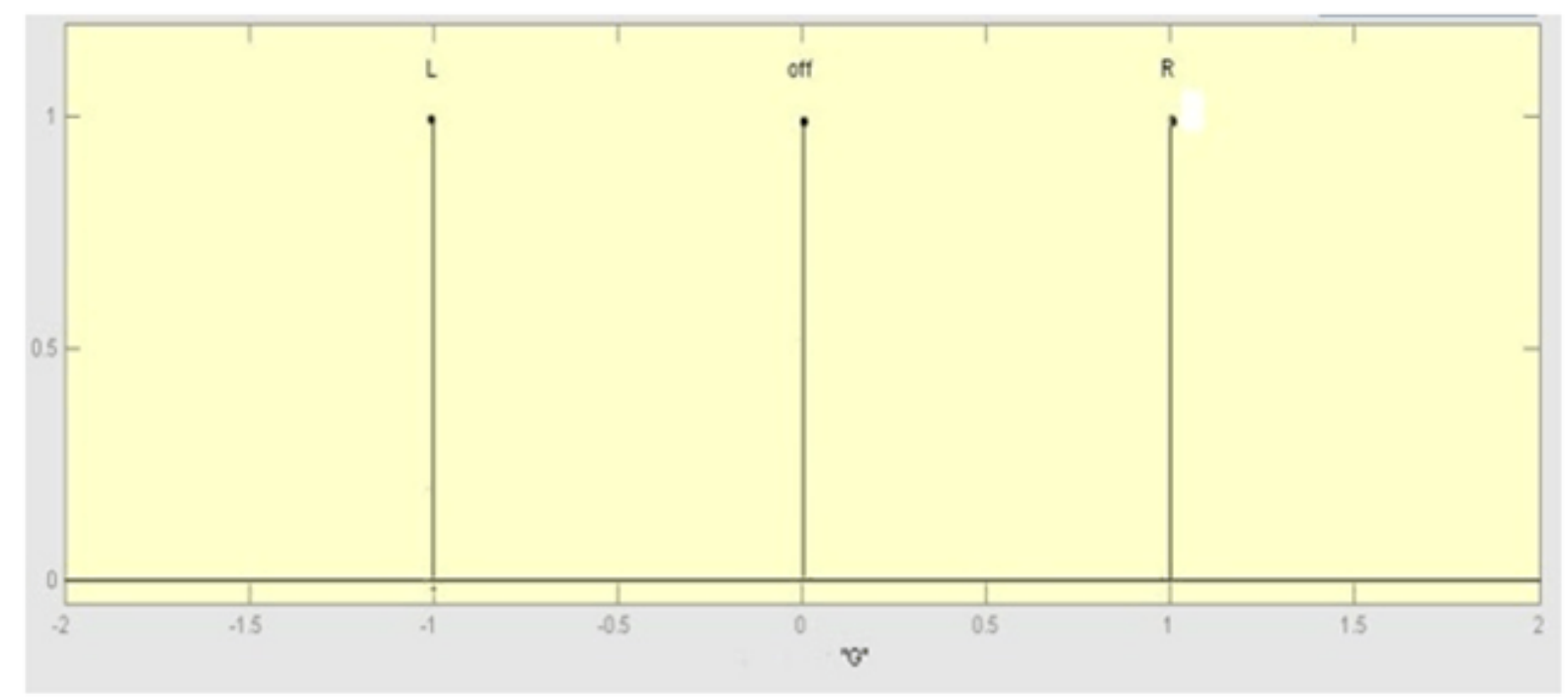

Figure 6. Membership function for turn signal lights.

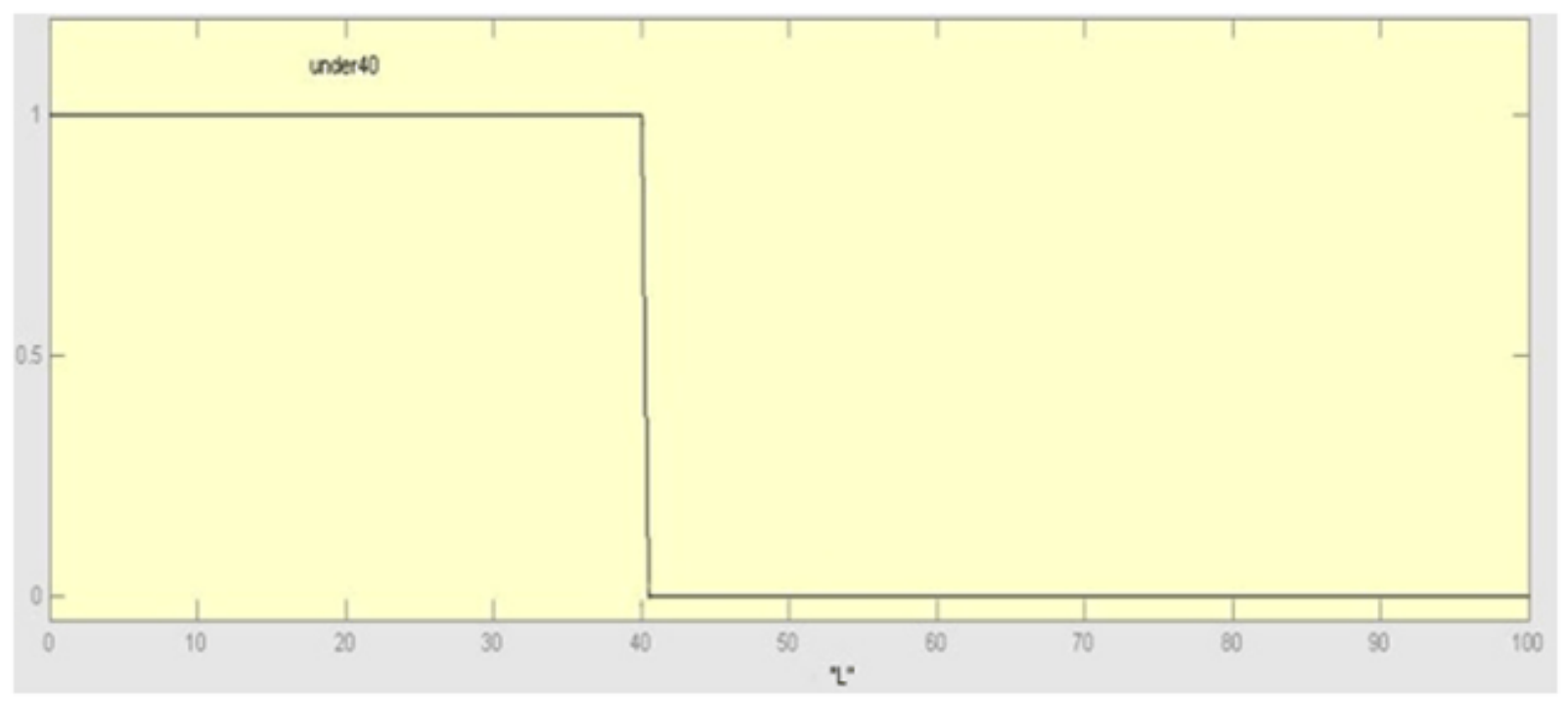

Figure 7. Membership function for distance travelled by car. 


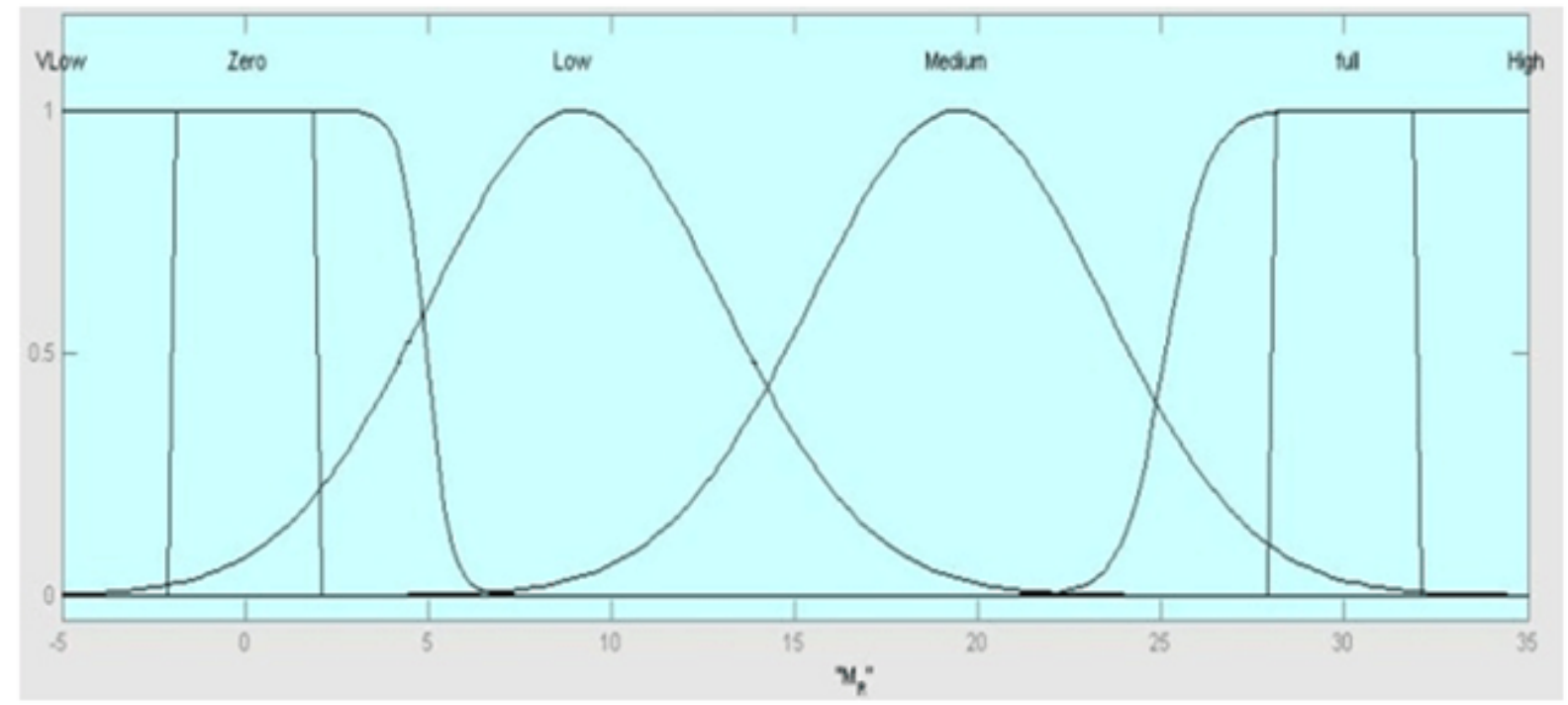

Figure 8. Membership function for mirror angle.

\subsection{Turn Signal Lights}

As a standard to leave side parking, a driver should use turn signal light. In fact, when the driver wants to turn car's direction, using of turn signals is necessary to aware other drivers of his rounding. Consequently, moving from parking lot is a kind of change in direction, thus using these lights is another characteristic of this movement. In our system, using turn signal is a key factor to start acting, but by switching off turn signals the system is still working. Indeed, this parameter is not a limitation. In the following, the membership function for this parameter is presented in Fig. 6.

\subsection{Distance Travelled from Parked Position}

In this situation we want to define a variable which is another limitation for the acting of leaving side street parking. It is obvious that a driver doesn't need long distance to get out of its parking lot. Thus, $\mathrm{L}$ is considered as the distance travelled by the car. When this variable reaches the upper-limit, it means the act of leaving parking is finished. From experiment, 40 meters is considered as maximum value of $\mathrm{L}$. Here, the membership function of this parameter is expressed in Fig.7.

\subsection{Primary Angle Mirrors Adjusted for Normal State}

Each driver should adjust angle of mirrors based on his/her body to have a good vision. It is known as one of the rules of driving. Our system considers this primary angle during its acting and makes its changing based on this angle This parameter sets the initial state value which is needed for determining mirror angle.

\subsection{Mirror Angle}

As it can be seen earlier, output parameter for this system is mirror angle. The schematic of its membership function is depicted in Fig.8.

Based on this experimental observation and defined variables and parameters, several rules were designed for operating the system. In fact, the relation between input and output data is a complex of these rules. In the following section, we use these rules to simulate our system, while the car is going out of the parking.

\section{Simulation and Results}

\subsection{Kinematic Model of a Car}

In this section, very simple kinematic model of steering a four-wheel vehicle is expressed. It is assumed that steering wheel can influence only front wheels. As you can see from Fig. 2, while front wheels' angles are not zero ( $\alpha 1$ and $\alpha 2)$, it can be considered that there are two circles with radius R1 and R2 which each wheel is turning around one of them. $\alpha 1$ and $\alpha 2$ are measures by mechanical sensors. These two radiuses intersect at point $\mathrm{C}$ which is called turn center. When the car has this position, the equations of car's motions are as follows:

$$
\begin{aligned}
& \frac{d x}{d t}=v \cos \alpha \cos \theta \\
& \frac{d y}{d t}=v \cos \alpha \sin \theta \\
& \frac{d \theta}{d t}=\frac{v}{L} \sin \alpha
\end{aligned}
$$

Where, the position of the car is $(\mathrm{x}, \mathrm{y}), \mathrm{t}$ is time, $\alpha 1$ and $\alpha 2$ are front wheels angle. $\alpha$ is the medium of these two angles. $\theta$ is the angel of a car relative to its first position. $\mathrm{V}$ is speed of the front wheel and $\mathrm{L}$ is distance between rear and front wheel. In this modeling, it is considered that the steering angle is calculated from equations of motion, but in our system, as it is mentioned earlier, this angle is measured by gyroscope. 


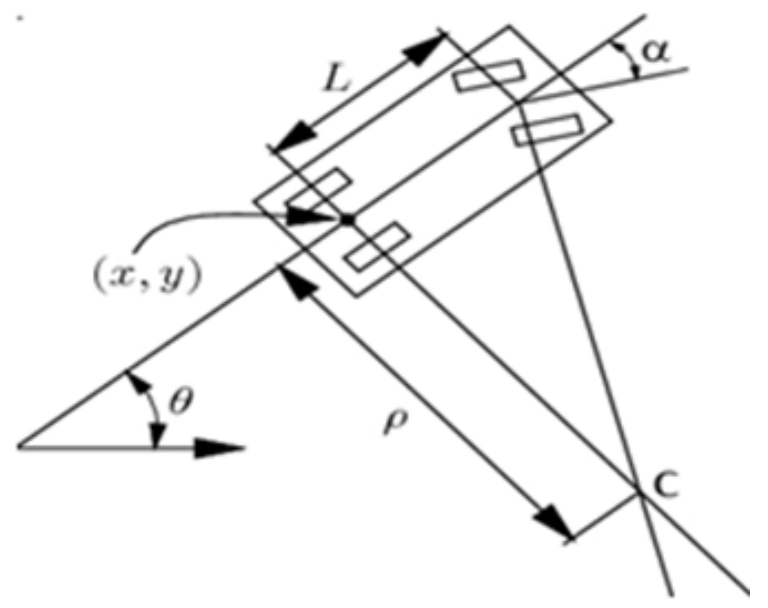

Figure 9. Kinematic model (simple model) for a car and front wheel

\subsection{Simulation of an Example}

In this part, it is considered; our car is parked between two other cars in the street side. And the driver decides to get the car out the parking. The schematic of this practice is depicted in Fig.10. First, driver should switch the car on and then changes the gear in to drive mode and in manual state involves first gear. After that, driver turns on the left turn signal. If he/she does not switch on turn signal or turns on right turn signal light, the system may not work. During leaving side street parking, as the driver turns his/her car and the steering angle is increasing from $0^{\circ}$ to $45^{\circ}$ counter-clockwise the system changes the angle of left side mirror clockwise from the initial set value to its final limit. If steering angle exceeds $45^{\circ}$, the value of mirror angle remains constant in its extremity and while the driver decrease the steering angle to place the car in the direction of the road, the mirror angle amount turns back to its primary value. During this practice, if travelled distance or speed of car is reached to limitation, the system is restarted.

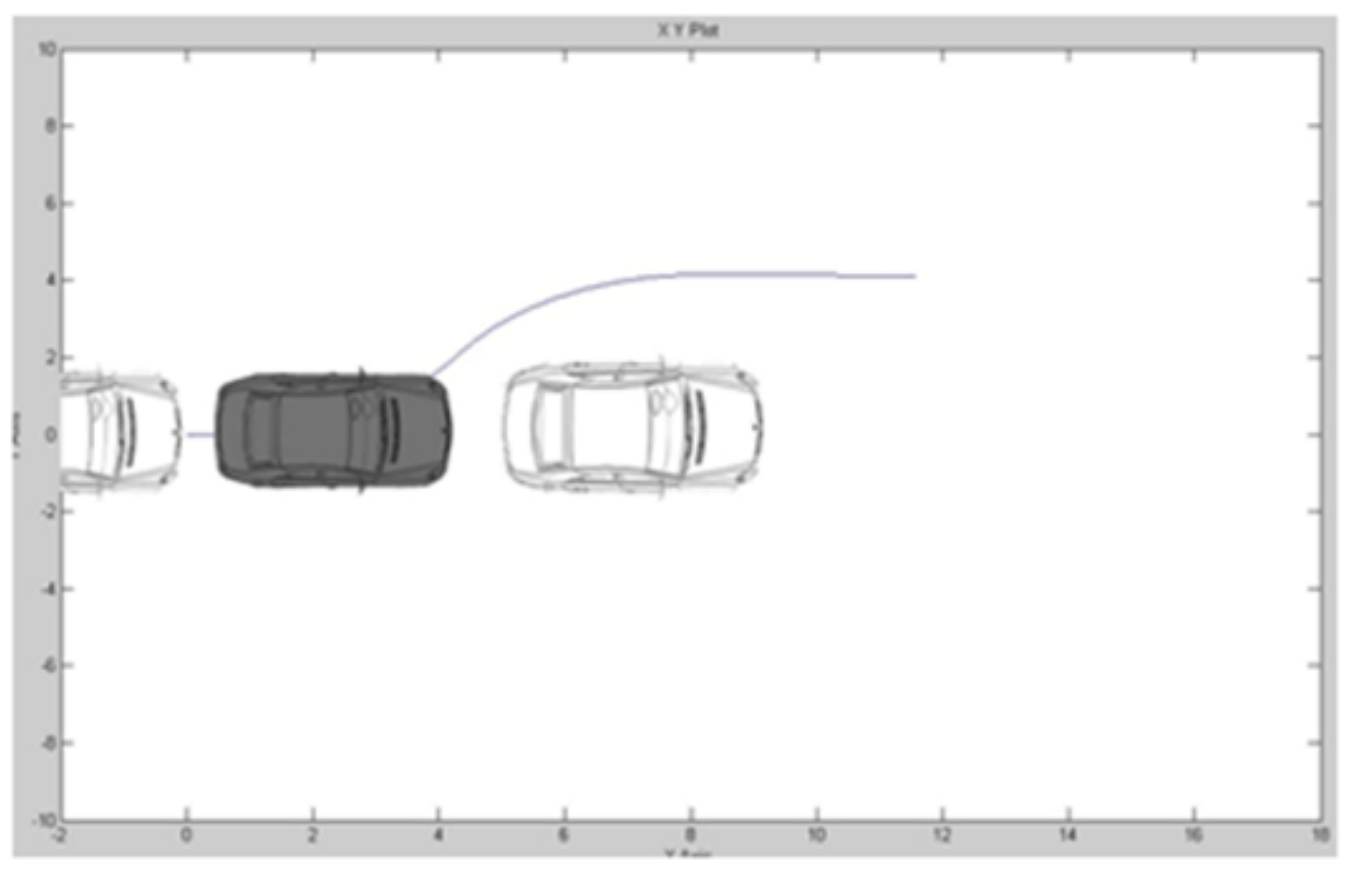

Figure 10. The path of leaving side parking for gray car which is parked between two other cars (white)

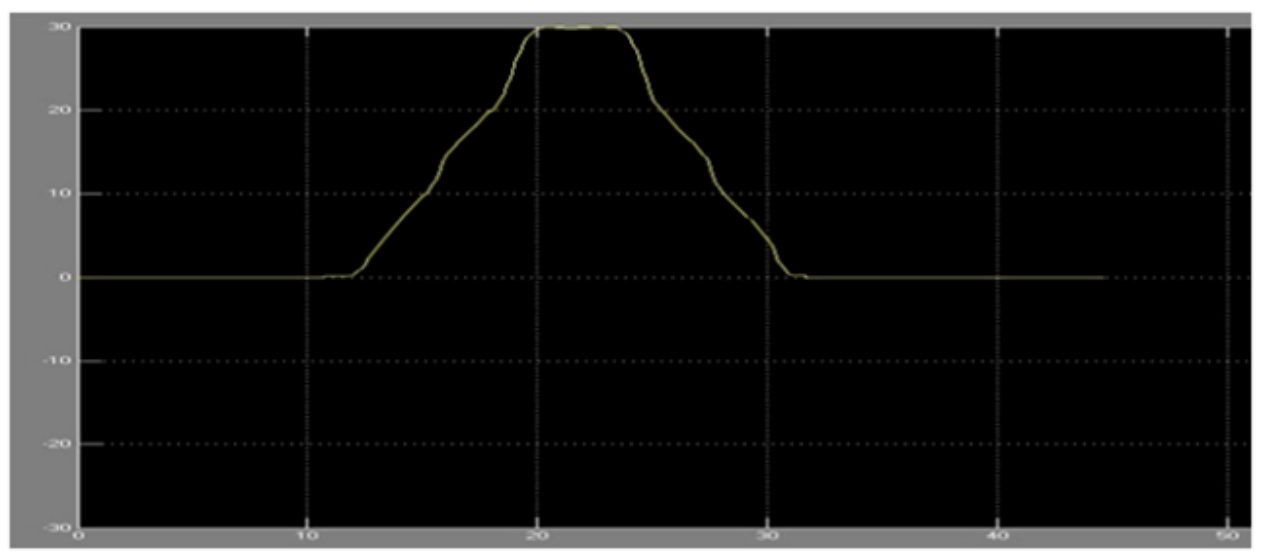

Figure 11. mirror angle changing during system performance. 


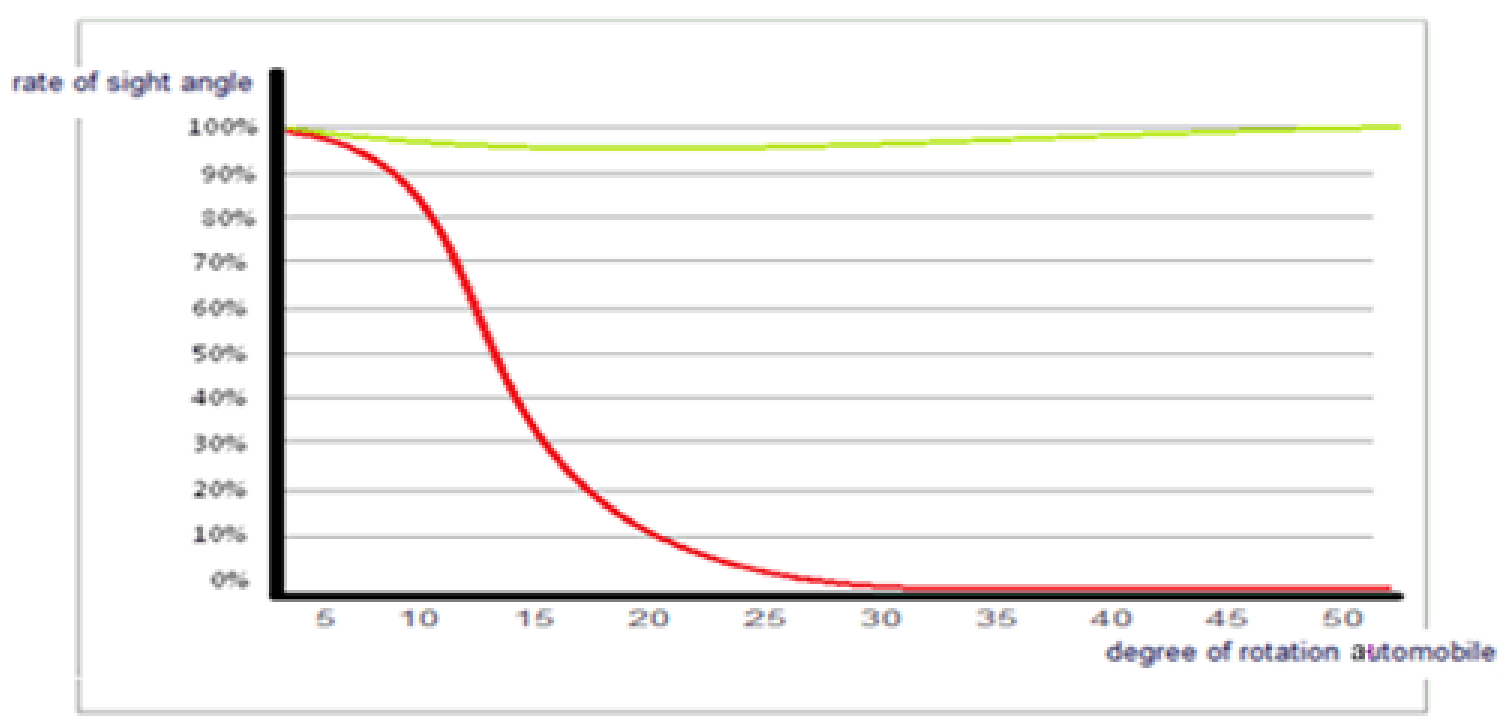

\section{sight angle of mirror after applying system \\ n sight angle of mirror before applying system \\ sight angle of mirror at the time of going out of parking}

Figure 12. The schematic of improvement in visibility by applying the system

\subsection{Result}

In this simulation, if the driver acts based on conditions of system, the system performs properly and it results in changing the mirror angle. Altering of mirror angle is presented in fig. 11 .

\subsection{Advantages}

The system we designed has advantages beside its simplicity which can be listed as follow.

1- Altering the angle of side-mirrors to compensate turning angle of the car which results in enhancing visibility and removing the blind spot while the car is leaving the side park. This improvement in visibility is shown in Fig. 12.

2-As a result of designation of system based on parameters which are available in any automobiles, the system can easily be installed on any cars without any restrictions.

3-Installation of the system has low executive costs thus; mass production of the system is economical.

4-In comparison with sensors, our system has two advantages. First, the system is less expensive; second, it is more reliable than using sensors. So, installation of the system instead of sensors reduces costs and increases safety of vehicle.

\section{Conclusion}

Side mirrors are very important instrument which are installed in a car. However, these mirrors help to better vision, yet areas that are called blind spots are places which drivers should be aware of them. Also it is known that, these kinds of areas increase the disturbing in traffic which results in enhancing probability of accidents. For instance, a usual type of car crashing is happening when driver wants to get out of side car parking. In this article, we designed a controller, based on fuzzy control that decreases the possibility of car crashing.

\section{REFERENCES}

[1] http://www.marmon.com, accessed November 2011

[2] Salem, M., and Aly, A.: 'Fuzzy Control of a Quarter-Car Suspension System', World Academy of Science, Engineering and Technology, 2009, 53, pp. 258-263.

[3] Flannagan, M.J., Reed, M.P.: 'Geometric Visibility of Mirror-Mounted Turn Signals', AE 2005 World Congress \& Exhibition, 2005-01-0449.

[4] http://www.opticampus.com, accessed November 2011

[5] Lin, T.C., Roopaei, M. and Chen, M.C.: 'Car Suspension Control by Indirect Adaptive Interval Type-2 Fuzzy Neural Network Control', World Applied Sciences Journal, 2010, 8, pp. 555-564.

[6] Nasution, H.: 'Development of fuzzy logic control for vehicle 
air conditioning system', Telkomnika, 2008, 6(2), pp. 73-82.

[7] Chai, L., Gong, M., Liu, X., Zhang, X., Hu, C.: 'Implementation of Fuzzy-PID in Smart Car Control', Journal of Measurement Science and Instrumentation, 2010, 1, pp. 75-77.
[8] Zadeh, L.A.: 'Fuzzy Sets', Information and Control,1965, 8, pp. 338-353.

[9] Tong, R.M.: 'A Control Engineering Review of Fuzzy Systems', Automotico, 1977, 13, pp. 559-569. 